\title{
S-1 in the treatment of advanced and recurrent gastric cancer: current state and future prospects
}

\author{
Ikuo Takahashi, Yoshiniro Kakej, Yasunori Emi, Masato Sakurai, Yusuke Yonemura, Yasue Kimura, \\ and Yoshiniko MaEHaRa \\ Department of Surgery and Science, Graduate School of Medical Sciences, Kyushu University, 3-1-1 Maidashi, Higashi-ku, Fukuoka \\ 812-8582, Japan
}

\begin{abstract}
Background. S-1 (TS-1 $\left.{ }^{\circledR}\right)$ is a novel oral anticancer drug. Because of the excellent results of phase II studies, we continued to prescribe $S-1$ for advanced or recurrent gastric cancer after we participated in the phase I and II studies.

Methods. Twenty-nine patients with advanced or recurrent gastric cancer were treated with S-1. Clinicopathological features, survival, and adverse reactions were analyzed.

Results. One course of treatment consisted of 40,50 , or $60 \mathrm{mg} /$ body twice a day for 28 days followed by withdrawal for 2 weeks. The mean number of treatments was 3.6 courses (range, 1-12 courses). The response rate was 37.9\% (11 partial responses [PRs] in 29 patients). Although the response rate of patients who did not receive prior chemotherapy was $\mathbf{4 7 . 6} \%$ (10 PRs in 21 patients), that of patients with prior chemotherapy was $12.5 \%$ (1 PR in 8 patients). The median survival time was 14.1 months, and that of patients who responded to treatment was 22.1 months, which was significantly longer than that of nonresponder patients. One-year and 2-year survivals in the 29 patients were $50.2 \%$ and $24.3 \%$, respectively. Adverse reactions were noted in 17 of 29 patients, and the most frequent one was leukocytopenia. Only 2 patients experienced grade 3 leukocytopenia and neutrocytopenia.

Conclusion. Because of the high response rate and low incidence of severe adverse reactions, $S-1$ is a first-line chemotherapy that can be used for outpatients, especially for patients without prior chemotherapy. As the response rate for patients with prior chemotherapy was low, combined therapy with $\mathrm{S}-1$ is worth evaluating for these patients.
\end{abstract}

Key words S-1 - Gastric cancer · Combined therapy

\section{Introduction}

S-1 is a novel oral anticancer drug, which was developed based on the biochemical modulation of tegafur (FT) by 5-chloro-2,4-dihydroxypyridine (gimeracil) and pot-

Offprint requests to: I. Takahashi

Received: October 29, 2002 / Accepted: January 28, 2003 assium oxonate (oteracil) in a molar ratio of 1:0.4:1 [1-4]. FT is a prodrug of 5-fluorouracil (5-FU), an active drug against various forms of gastrointestinal malignancy. 5 -FU is degraded to $\alpha$-fluoro- $\beta$-alanine by dihydropyrimidine dehydrogenase (DPD), which is produced in various organs, including tumor tissue [5,6]. Gimeracil strongly inhibits DPD, which results in a prolonged increased concentration of 5-FU in the plasma [7]. Oteracil inhibits the phosphorylation of 5-FU to 5-fluorouridine-5'-monophosphate [4]. As oteracil is distributed in the gastrointestinal tract after oral administration, it possibly decreases 5-FU-induced gastrointestinal tract toxicity [4]. In short, S-1 was designed both to increase antitumor activity and to reduce druginduced adverse reactions.

The results of independent sets of phase II studies of S-1 were excellent [8-10]. Sakata et al. [9] showed that, in 51 patients with advanced gastric cancer, the response rate of S-1 administration was $49 \%$. The independent study of Koizumi et al. [10] showed a response rate of $44 \%$. Because of these results, we have continued to prescribe S-1 as a first- and second-line chemotherapy for recurrent and far-advanced gastric cancer, after we participated in the phase I and phase II studies of this drug. In this report, we describe our clinical experience of S-1 and discuss its future prospects.

\section{Patients and methods}

\section{Patient criteria}

The criteria for patients included in this study were: (1) histologically documented advanced gastric cancer and histologically or clinically proven recurrent gastric cancer; (2) measurable or evaluable disease; (3) recovery from all adverse reactions of prior therapies more than 4 weeks after completion of prior chemotherapy; (4) an 
Eastern Cooperative Oncology Group performance status of $0-2 ;$ (5) adequate organ function (white blood cell count, $\geqq 3000 / \mathrm{mm}^{3}$; absolute neutrocyte count, $\geqq 2000 / \mathrm{mm}^{3}$; platelet count, $\geqq 100000 / \mathrm{mm}^{3}$; hemoglobin, $\geqq 9.5 \mathrm{~g} / \mathrm{dl}$; transaminase level without liver metastases, $\leqq 2.5$ times upper normal limit, or with liver metastases, $\leqq 3.0$ times upper normal limit; total bilirubin, $\leqq 1.5 \mathrm{mg} /$ $\mathrm{dl}$; serum albumin, $\geqq 3.0 \mathrm{~g} / \mathrm{dl}$; serum creatinine and blood urea nitrogen, §upper normal limit). Presence of prior chemotherapy (including adjuvant chemotherapy) was not considered a criterion for exclusion. Treatment with S-1 started from May 1994 and continued to December 2000.

\section{Treatment schedule}

S-1 was provided by Taiho Pharmaceutical Company (Tokyo, Japan). The dose of S-1 was determined based on the body surface area (BSA) of the patient. The following doses were administered orally, twice daily, after breakfast and dinner; BSA, less than $1.25 \mathrm{~m}^{2}$, $40 \mathrm{mg}$; BSA $1.25-1.5 \mathrm{~m}^{2}, 50 \mathrm{mg}$; BSA, $1.5 \mathrm{~m}^{2}$ or more, $60 \mathrm{mg}$. One course of treatment consisted of 28 consecutive days' administration followed by 14 days' rest.

Treatment was interrupted or the doses were reduced after hematological toxicity of more than grade 3 or nonhematological toxicity of more than grade 2 appeared.

\section{Assessment of responses and adverse reactions}

The antitumor effects and adverse reactions were evaluated in accordance with the criteria of the Japanese Research Society for Gastric Cancer [11,12] and the criteria of the Japan Society for Cancer Therapy [13], which were established based on criteria established by the World Health Organization (WHO). The criteria to evaluate antiumor effects were as follows: complete response (CR), eradication of all cancers and maintenance of the condition for 4 weeks or more; partial response (PR), $50 \%$ or more reduction in size of lesions and maintenance of the condition for 4 weeks or more; no change (NC), less than $50 \%$ reduction in size of lesions or enlargement of lesions within $25 \%$ and maintenance of the condition for 4 weeks or more; progressive disease (PD), $25 \%$ or more enlargement of lesions or appearance of new lesions. Primary gastric lesions can be classified into three types: (a) measurable lesions, (b) evaluable but not measurable, and (c) diffusely infiltrating. Measurable lesions can be assessed by gastography with the patients in the same position for each procedure. Evaluable but not measurable lesions can be evaluated as a PR by improvements in gastrographic or endoscopic findings, or both, which are clearly different from pretreatment findings, e.g., show- ing a marked regression of tumors and ulcerations or marked flattening of evaluated lesions that can be estimated as a regression of more than $50 \%$ for 4 weeks or more. Diffusely infiltrating lesions can be evaluated by expansion of the affected gastric lumen, as seen by gastrography measured with a planimeter or a computer image analysis system before and after treatment. The gastrography must be done with the patient in the same position each time, using the same volume of barium and intake of air. PR after 4 or more weeks can be confirmed by enlargement of $50 \%$ or more of the affected area, compared with findings before treatment.

The overall response was evaluated from the WHO criteria. The response rate was defined as: response rate $(\%)=$ (number of patients with $\mathrm{CR}$ and $\mathrm{PR}$ after treatment/number of patients who received treatment ) $\times 100$.

The survival time was calculated as the time from the start of treatment until death or final follow-up. The survival was calculated by statistical analysis, using the Kaplan-Meier method. Statistical analysis of differences between the survival curves were assessed by the generalized Wilcoxon test.

\section{Results}

\section{Characteristics of the patients}

Table 1 shows the clinical features of the 23 male and 6 female patients evaluated in this study. In regard to the state of the evaluable lesions, 13 patients had not had an operation, 4 had had an operation but were incurable and, 12 had recurrence of tumors after a previous curative operation. Twenty-one patients had no history of prior chemotherapy, and 8 patients had already received chemotherapy for recurrent lesions.

\section{Response rate and survival}

All patients showed antitumor effects and some had adverse reactions. The mean number of treatments was 3.6 courses (range, 1-12 courses). Table 2 shows the antitumor activity of S-1 for all patients. PR was obtained in $37.9 \%$ of the patients (11 of 29). When the antitumor activity was evaluated according to the site of the disease, the response rate of primary tumors was $45.5 \%$ (5 of 11 patients); lymph nodes, $41.4 \%$ (7 of 17 patients); and liver metastasis, $30.0 \%$ (3 of 10 patients).

Table 3 shows the antitumor activity of S- 1 for the patients without prior chemotherapy. In this group, patients with marked antitumor activity had a response rate of $47.6 \%$ (10 of 21 patients). When antitumor activity was evaluated by site of disease, the response rate for primary tumors was $45.4 \%$ ( 5 of 11 patients), for lymph 
Table 1. Characteristics of the patients

\begin{tabular}{|c|c|c|c|}
\hline Age (years) & $60.4 \pm 15.3$ & (Range, 34-83) & \\
\hline \multicolumn{4}{|l|}{ Sex } \\
\hline Male & 23 & & \\
\hline Female & 6 & & \\
\hline \multicolumn{4}{|l|}{ Type of lesion } \\
\hline Unresectable & 13 & & \\
\hline Incurable & 4 & & \\
\hline Recurrence & 12 & & \\
\hline \multicolumn{4}{|l|}{ Histological type } \\
\hline Differentiated & 16 & & \\
\hline Undifferentiated & 13 & & \\
\hline \multicolumn{4}{|l|}{ Prior chemotherapy } \\
\hline$(-)$ & 21 & & \\
\hline \multirow[t]{7}{*}{$(+)$} & 8 & $\mathrm{UFT}+\mathrm{PSK}$ & 2 \\
\hline & & $\mathrm{CDDP}+\mathrm{FT} \rightarrow \mathrm{UFT}+\mathrm{PSK}$ & 1 \\
\hline & & $\mathrm{FT}+\mathrm{MMC}$ & 1 \\
\hline & & $\mathrm{MTX}+5-\mathrm{FU}$ & 1 \\
\hline & & $\mathrm{UFT} \rightarrow \mathrm{MTX}+5-\mathrm{FU}$ & 1 \\
\hline & & 5'dFUR & 1 \\
\hline & & FP & 1 \\
\hline \multicolumn{4}{|l|}{ Performance status } \\
\hline $0-1$ & 26 & & \\
\hline 2 & 3 & & \\
\hline
\end{tabular}

Table 2. Response to treatment in all patients $(n=29)$

\begin{tabular}{lcccc}
\hline & \multicolumn{4}{c}{ Response } \\
\cline { 2 - 5 } & PR & NC & PD & Response rate \\
\hline All patients & 11 & 7 & 11 & $37.9 \%(11 / 29)$ \\
Site of disease & & & & \\
$\quad$ Primary tumor & 5 & 3 & 3 & $45.4 \%(5 / 11)$ \\
$\quad$ Lymph nodes & 7 & 4 & 6 & $41.4 \%(7 / 17)$ \\
Local recurrence & 1 & & & $100 \%(1 / 1)$ \\
Liver metastases & 3 & 3 & 4 & $30.0 \%(3 / 10)$ \\
Lung metastases & & & 1 & $0 \%(0 / 1)$ \\
\hline
\end{tabular}

$\mathrm{PR}$, Partial response; NC, no change; $\mathrm{PD}$, progressive disease

Table 3. Response to treatment in patients without prior chemotherapy $(n=21)$

\begin{tabular}{lcccc}
\hline & \multicolumn{4}{c}{ Response } \\
\cline { 2 - 5 } & PR & NC & PD & Response rate \\
\hline All patients & 10 & 5 & 6 & $47.6 \%(10 / 21)$ \\
Site of disease & & & & \\
$\quad$ Primary tumor & 5 & 3 & 3 & $45.4 \%(5 / 11)$ \\
$\quad$ Lymph nodes & 6 & 4 & 1 & $54.5 \%(6 / 11)$ \\
Local recurrence & 1 & & & $100 \%(1 / 1)$ \\
Liver metastases & 3 & 1 & 4 & $37.5 \%(3 / 8)$ \\
$\quad$ Lung metastases & & & 1 & $0 \%(0 / 1)$ \\
\hline
\end{tabular}

$\mathrm{PR}$, Partial response; NC, no change; $\mathrm{PD}$, progressive disease
Table 4. Response to treatment in patients who received prior chemotherapy $(n=8)$

\begin{tabular}{lcccr}
\hline & \multicolumn{4}{c}{ Response } \\
\cline { 2 - 5 } & PR & NC & PD & Response rate \\
\hline $\begin{array}{l}\text { All patients } \\
\text { Site of disease }\end{array}$ & 1 & 2 & 5 & $12.5 \%(1 / 8)$ \\
$\quad \begin{array}{l}\text { Lymph nodes } \\
\text { Liver metastases }\end{array}$ & 1 & 0 & 5 & $16.7 \%(1 / 6)$ \\
& & 2 & 0 & $0 \%(0 / 2)$ \\
\hline
\end{tabular}

PR, Partial response; NC, no change; PD, progressive disease

node, $54.5 \%$ (6 of 11 patients); and for liver metastases, $37.5 \%$ ( 3 of 8 patients). Table 4 summarizes the clinical response to $S-1$ in the 8 patients who had received other chemotherapy previously. The response rate was low: $12.5 \%$ ( 1 of 8 patients). The only patient in this group who showed PR was one with lymph node metastases who had previously received 5-FU + methotrexate therapy.

Figure 1 shows the survival of all patients. The 1-year and 2-year survivals of all patients were $50.2 \%$ and $24.3 \%$, respectively. Figure 2 shows the survivals according to the response to the treatment. In patients who showed PR after S-1 treatment, 1-year and 2-year survivals were $89.2 \%$ and $64.3 \%$, respectively. In patients who did not respond to treatment, 1-year survival 


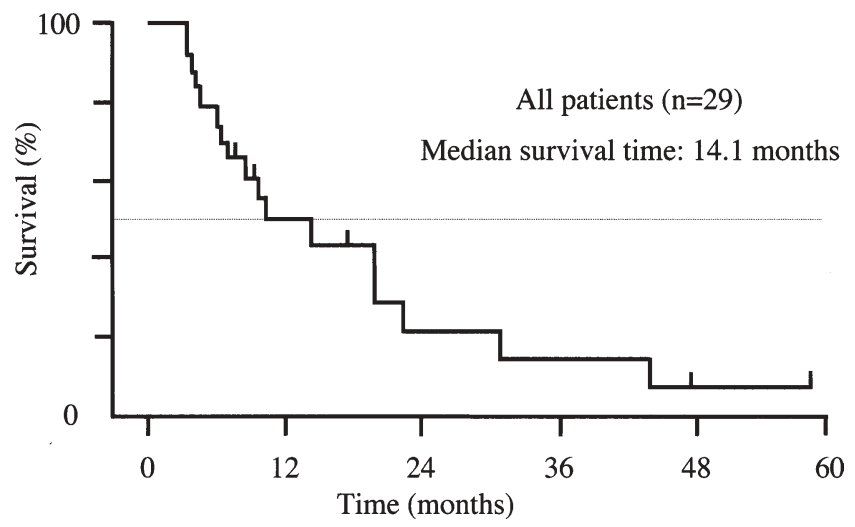

Fig. 1. Survival of all patients treated with $S-1(n=29)$

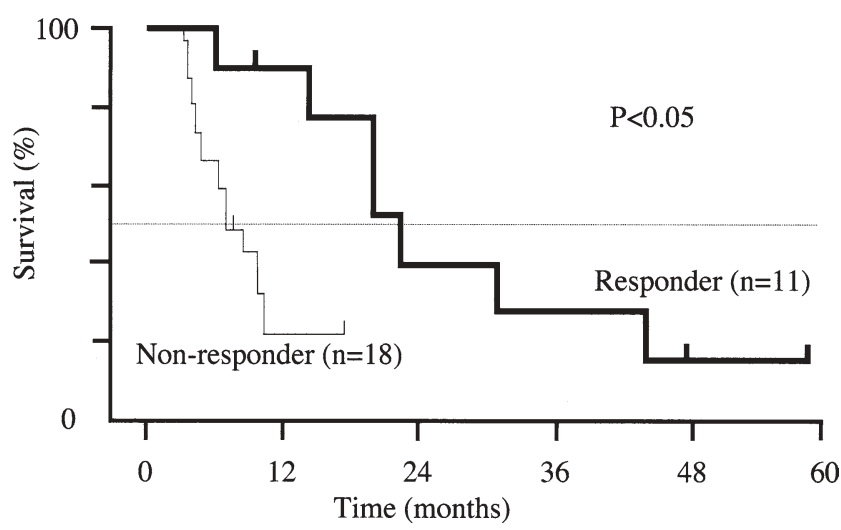

Fig. 2. Treatment response and survival of the patients. Thick line, Patients who responded to S-1 treatment $(n=11)$; thin line, patients who failed S-1 treatment $(n=18)$

was only $21.1 \%$, and no patients survived for more than 2 years.

The median survival time of all patients $(n=29)$ was 14.1 months. The median survival time of patients who showed a PR $(n=11)$ was 22.1 months, but in patients who failed S-1 treatment, it was only 6.0 months.

\section{Adverse reactions}

Table 5 summarizes adverse reactions of all grades during and after the treatment. Adverse reactions occurred in $58.6 \%$ of patients (17 of 29$)$. The most frequent adverse reaction was myelosuppression, such as leukocytopenia $(34.3 \% ; 10$ of 29 patients), followed by neutrocytopenia (31.0\%; 9 of 29 patients), and anemia (13.8\%; 4 of 29 patients). For nonhematological toxicity, diarrhea ( 2 of 29 patients) and skin changes (2 of 29 patients) were most frequent. In all patients, only 2 experienced grade 3 toxicity (leukocytopenia and neutrocytopenia). No grade 4 adverse reactions appeared. There were no chemotherapy-related deaths.
Table 5. Adverse reactions $(n=29)$

\begin{tabular}{|c|c|c|c|c|c|}
\hline & \multicolumn{5}{|c|}{ Grade } \\
\hline & 4 & 3 & 2 & 1 & $\begin{array}{c}\text { Total } \\
\text { (incidence }[\%] \text { ) }\end{array}$ \\
\hline \multicolumn{6}{|l|}{ Hematological } \\
\hline Leukocytopenia & & 2 & 3 & 5 & $10(34.3 \%)$ \\
\hline Neutrocytopenia & & 2 & 3 & 4 & $9(31.0 \%)$ \\
\hline Anemia & & & 2 & 2 & $4(13.4 \%)$ \\
\hline Thrombocytopenia & & & 1 & 1 & $2(6.9 \%)$ \\
\hline \multicolumn{6}{|l|}{ Nonhematological } \\
\hline Diarrhea & & & 1 & 1 & $2(6.9 \%)$ \\
\hline Stomatitis & & & & 1 & $1(3.4 \%)$ \\
\hline Nausea, vomiting & & & & 1 & $1(3.4 \%)$ \\
\hline Pigmentation, eruption & & & & 2 & $2(6.9 \%)$ \\
\hline
\end{tabular}

\section{Discussion}

Continuous infusion is an effective method to administer 5-FU [14-17]. Low-dose 5-FU and cisplatin (CDDP) treatment were frequently used in Japan in the 1990s because of low toxicity and high antitumor activity [1820]. This treatment has the advantage of continuous infusion of 5-FU and biochemical modulation of CDDP [21]. Chung et al. [19] reported that, in a total of 26 patients with advanced or recurrent gastric cancer, the overall response rate was $50 \%$, with 2 patients having a complete response (CR). The disadvantage of this treatment was longterm hospitalization during treatment.

S-1 is a novel oral anticancer drug, which was developed based on the biochemical modulation of FT by gimeracil and oteracil [1-4]. Gimeracil strongly inhibits DPD, and inhibits 5-FU degradation approximately 180 times more effectively than uracil in vitro [7]. Coadministration of gimeracil and FT markedly increases the antitumor activity of FT. Oteracil inhibits the phosphorylation of 5-FU to 5-fluorouridine-5'monophosphate. As oteracil is distributed in the gastrointestinal tract after oral administration, it possibly decreases 5-FU-induced gastrointestinal tract toxicity [4]. Thus, S-1 produces a prolonged plasma 5-FU concentration with reduced toxicity, and at the same time enables outpatient chemotherapy. Pharmacokinetically, with the standard drug dose (twice daily, after meals; BSA, $<1.25 \mathrm{~m}^{2}, 40 \mathrm{mg}$; BSA, $1.25 \mathrm{~m}^{2}-1.5 \mathrm{~m}^{2}, 50 \mathrm{mg}$; BSA, $\geqq 1.5 \mathrm{~m}^{2}, 60 \mathrm{mg}$; consecutive 28-day administration and then 14 days' rest), the plasma 5-FU concentration is similar to that of continuous 5-FU infusion [22].

Within the past 10 years, new anticancer drugs have been used in Japan. Response rates for single administration of these drugs were: irinotecan, $18.4 \%$ (14 of 76 patients); pirarubicin, $10.2 \%$ (5 of 49 patients); CDDP, $18.3 \%$ (13 of 71 patients); epirubicin, $14.7 \%$ (5 of 34 patients); and docetaxel, 23.7\% (14 of 59 patients) [23- 
25]. The response rates to $S-1$ in the two independent phase II studies of patients without prior chemotherapy were $49 \%$ and $44 \%[9,10]$. Our data showed that the response rate to $\mathrm{S}-1$ in all patients was $37.9 \%$. These data indicate that $\mathrm{S}-1$ has the highest response rate after single-drug administration. When combined therapy frequently prescribed for advanced or recurrent gastric cancer was considered, FAMTX (5-FU + adriamycin + methotrexate [MTX]) therapy showed response rates of $21 \%-44 \%$ [26-29], ECF (epirubicin + CDDP + 5-FU) therapy showed response rates of $45 \%-46 \%[27,28]$, and 5-FU + CDDP (FP) showed a response rate of $43 \%$ [30]. Thus, the antitumor effect of S-1 was comparable to these therapies.

The median survival of patients treated by S- 1 in our study was 14.1 months in all patients. Phase II studies of S-1 showed median survivals of 207 days and 250 days $[9,10]$. Among other combined therapies, FAMTX showed a median survival of 5.7-8.7 months [26-29], FP showed 7.0 months [30], and ECF showed 8.7-8.9 months $[27,28]$. Because of the high response rate and longer survival, $\mathrm{S}-1$ is surely a key drug in the treatment of advanced and recurrent gastric cancer.

For outpatient chemotherapy, a low incidence of severe adverse reactions is especially important. Our data showed that the frequency of adverse reactions of grade 3 or more was $6.9 \%$, and this finding was consistent with frequencies of $4.0 \%$ and $5.9 \%$ of grade 3 or more adverse reactions in the previous phase II studies. From the viewpoint of safety, S-1 is appropriate for outpatient chemotherapy.

Although a high response rate to S-1 was reported for the phase II studies, these studies included only patients who had no evidence of prior chemotherapy. When only patients with a history of prior chemotherapy were considered, our study showed a low response rate (12.5\%; one PR in eight patients). Thus, a new treatment strategy should be established. combined therapy of S-1 with other anticancer drugs is a future project to improve the response to chemotherapy. Although combined therapy with CDDP was investigated [31], we are now focusing on the combined therapy of S-1 and taxotere. The following data support this concept: (1) combined 5-FU and a taxane (paclitaxel) in vitro was proved to show supra-additive effects [32]; (2) 5-FU resistance was overcome by docetaxel in vitro [33]; (3) clinically, taxotere was cytotoxic regardless of prior chemotherapy $[24,25]$; and (4) the cytotoxicity of S-1 was increased by docetaxel in a study using gastric cancer xenografts (Takahashi et al., unpublished data). A phase I study of combined S- 1 and taxotere is ongoing. Another approach to improve survival may be to find factors that predict the response to $\mathrm{S}-1$, as our data clearly showed a better survival of responders than of nonresponders (Fig. 2). A definite conclusion cannot be made. Miyamoto et al. [34] retrospectively examined whether the immunoreactivity of thymidylate synthase and DPD in biopsy specimens could predict the response to S-1. Contrary to expectations, S-1 was effective, regardless of the immunohistochemical expression of both enzymes, in their study.

In conclusion, $\mathrm{S}-1$ should be used as first-line chemotherapy for advanced and recurrent gastric cancer. The establishment of a strategy for second-line chemotherapy with S-1 and taxotere, and the identification of factors that predict responses are urgent tasks to improve the survival rate of patients.

\section{References}

1. Takechi T, Nakano K, Uchida J, Mita A, Toko K, Takeda S, et al. Antitumor activity and low intestinal toxicity of S-1, a new formulation of oral tegafur, in experimental tumor models in rats. Cancer Chemother Pharmacol 1997;39:205-11.

2. Fukushima M, Shimamoto Y, Kato T, Uchida J, Yonekura R, Ohshimo H, et al. Anticancer activity and toxicity of S-1, an oral combination of tegafur and two biochemical modulators, compared with continuous infusion of 5-fluorouracil. Anticancer Drugs 1998;9:817-23.

3. Fukushima M, Satake H, Uchida J, Shimamoto Y, Kato T, Takechi T, et al. Preclinical antitumor efficacy of S-1 2-a: a new oral formulation of 5-fluorouracil on human tumor xenografts. Int J Oncol 1998;13:693-8.

4. Shirasaka T, Shimamoto Y, Fukushima M. Inhibition by oxonic acid of gastrointestinal toxicity of 5-fluorouracil without loss of its antitumor activity in rats. Cancer Res 1993;53:4004-9.

5. Maehara Y, Nagayama S, Okazaki H, Nakamura H, Shirasasa T, Fujii S. Metabolism of 5-fluorouracil in various human normal and tumor tissues. Gann 1981;72:824-7.

6. Etienne MC, Cheradame S, Fischel JL, Formento FP, Dassonville $\mathrm{O}$, Renee $\mathrm{N}$, et al. Response to fluorouracil therapy in cancer patients: the role of tumoral dihydropyrimidine dehydrogenase activity. J Clin Oncol 1995;13:1663-70.

7. Tatsumi K, Fukushima M, Shirasaka T, Fujii S. Inhibitory effects of pyrimidine, barbituric acid and pyridine derivatives on 5fluorouracil degradation in rat liver extracts. Jpn J Cancer Res (Gann) 1987;78:748-55.

8. Sugimachi K, Maehara Y, Horikoshi N, Shimada Y, Sakata Y, Mitachi Y, et al. An early phase II study of oral S-1, a newly developed 5-fluorouracil derivative for advanced and recurrent gastrointestinal cancers. Oncology 1999;57:202-10.

9. Sakata Y, Ohtsu A, Hirokoshi N, Sugimachi K, Mitachi Y, Taguchi T. Late phase II study of novel oral fluoropyrimidine anticancer drug S-1 ( $1 \mathrm{M}$ tegafur- $-0.4 \mathrm{M}$ gimestat- $1 \mathrm{M}$ otastat pottassium) in advanced gastric cancer patients. Eur J Cancer 1998;34:1715-20.

10. Koizumi W, Kurihara M, Nakano S, Hasegawa K, and the S-1 gastrointestinal cancer study group. Phase II study for S-1, a novel derivative of 5-fluorouracil, in advanced gastric cancer. Oncology 2000;58:191-7.

11. Japanese Research Society for Gastric Cancer, editors: General rules for gastric cancer study (in Japanese). 12th Ed. Tokyo: Kanehara; 1993. p 109-46.

12. Japanese Research Society for Gastric Cancer, editors: Japanese classification of gastric carcinoma. Part IV. Response assessment of chemotherapy for gastric carcinoma. 1st English Ed. Tokyo: Kanehara; 1995. p 90-104.

13. Japan Society for Cancer Therapy. Criteria for the evaluation of the clinical effects of solid cancer chemotherapy. J Jpn Soc Cancer Ther 1993;28:101-30. 
14. Lokich J, Ahlgren JD, Gullo JJ, Philips JA, Fryer JG. A prospective randomized comparison of continuous infusion 5-fluorouracil with a conventional bolus schedule in metastatic colorectal carcinoma: a mid-Atlantic oncology program study. J Clin Oncol 1989;7:425-32.

15. Hansen RM. 5-Fluorouracil by protracted venous infusion: a review of recent clinical studies. Cancer Invest 1991;9:637-42.

16. Yamao T, Shimada Y, Kondo H, Shirao K, Yokota T, Sugano K, et al. Clinical trial of continuous infusion of 5-fluorouracil using an ambulatory pump for metastatic colorectal cancer. Jpn J Clin Oncol 1995;25:46-50.

17. Moynihan T, Hansen R, Anderson T, Quebbeman E, Beatty P, Ausman R, et al. Continuous 5-fluorouracil infusion in advanced gastric carcinoma. Am J Clin Oncol 1988;11:461-4.

18. Kondo K, Murase M, Kodera Y, Akiyama S, Ito K, Yokoyama Y, et al. Feasibility study on protracted infusional 5-fluorouracil and consecutive low-dose cisplatin for advanced gastric cancer. Oncology 1996;53:64-7.

19. Chung YS, Yamashita Y, Inoue T, Matsuoka T, Nakata B, Onoda $\mathrm{N}$, et al. Continuous infusion of 5-fluorouracil and low dose cisplatin infusion for the treatment of advanced and recurrent gastric adenocarcinoma. Cancer 1997;80:1-7.

20. Kim R, Murakami S, Ohi Y, Inoue H, Yoshida K, Toge T. A phase II trial of low dose administration of 5-fluorouracil and cisplatin in patients with advanced and recurrent gastric cancer. Int J Oncol 1999;15:921-6.

21. Scanlon KJ, Newman EM, Lu Y, Priest DG. Biochemical basis for cisplatin and 5-fluorouracil synergism in human ovarian carcinoma cells. Proc Natl Acad Sci USA 1986;83:8923-5.

22. Hirata K, Horikoshi N, Aiba K, Okazaki M, Dennno R, Sasaki K, et al. Pharmacokinetic study of S-1, a novel oral fluorouracil antitumor drug. Clin Cancer Res 1999;5:2000-5.

23. Maehara Y, Sugimachi K, Kurihara M, Taguchi T. Clinical evaluation of S-1, a new anticancer agent, in patients with advanced gastrointestinal cancer (in Japanese with English abstract). Jpn J Cancer Chemother 1999;26:476-85.

24. Taguchi T, Sakata Y, Kanamaru R, Kurihara M, Suminaga M, Ohta J, et al. Late phase II clinical study of RP56976 (docetaxel) in patients with advanced/recurrent gastric cancer: a Japanese Cooperative Study Group trial (Group A) (in Japanese with English abstract). Jpn J Cancer Chemother 1998;25:1915-24.

25. Mai M, Sakata Y, Kanamaru R, Kurihara M, Suminaga M, Ohta J, et al. A late phase II study of RP56976 (docetaxel) in patients with advanced or recurrent gastric cancer: a Japanese Cooperative Study Group trial (Group B) (in Japanese with English abstract). Jpn J Cancer Chemother 1999;26:487-96.

26. Wils JA, Klein HO, Wagener DJ, Bleiberg H, Reis H, Korsten F, et al. Sequential high-dose methotrexate and fluorouracil combined with doxorubicin - a step ahead in the treatment of advanced gastric cancer: a trial of the EORTC Gastrointestinal Tract Cooperative Group. J Clin Oncol 1991;9;82731 .

27. Webb A, Cunningham D, Scarffe H, Harper P, Norman A, Joffe JK, et al. Randomized trial comparing epirubicin, cisplatin, and fluorouracil versus fluorouracil, doxorubicin, and methotrexate in advanced esophagogastric cancer. J Clin Oncol 1997;15: 261-7.

28. Waters JS, Norman A, Cunningham D, Scarffe JH, Webb A, Harper $\mathrm{P}$, et al. Long-term survival after epirubicin, cisplatin and fluorouracil for gastric cancer: results of a randomized trial. Br J Cancer 1999;80:269-72.

29. Kelsen D, Atiq OT, Saltz L, Niedzwiecki D, Ginn D, Chapman D, et al. FAMTX versus etoposide, doxorubicin, and cisplatin: a random assignment trial in gastric cancer. J Clin Oncol 1992;10: $541-8$.

30. Ohtsu A, Shimada Y, Yoshida S, Saito H, Seki S, Morise K, et al. Phase II study of protracted infusional 5-fluorouracil combined with cisplatinum for advanced gastric cancer: report from Japan Clinical Oncology Group (JCOG). Eur J Cancer 1994;30A:20913.

31. Ohtsu A, Boku N, Nakashima F, Koizumi W, Tanabe S, Saigenji $\mathrm{K}$, et al. A phase I/II study of S-1 plus cisplatin (CDDP) in patients with advanced gastric cancer (AGC). Proceedings of ASCO 2001;20:165.

32. Kano Y, Akutsu M, Tsunoda S, Ando J, Matsui J, Suzuki K, et al. Schedule-dependent interaction between paclitaxel and 5fluorouracil in human carcinoma cell lines in vitro. Br J Cancer 1996;74:704-10.

33. Hill BT, Whelan RDH, Shellard SA, Mcclean S, Hosking LK. Differential tumor cell lines and certain drug resistant sublines in vitro. Invest New Drugs 1994;12:169-82.

34. Miyamoto S, Boku N, Ohtsu A, Yoshida S, Ochiai A, Okabe H, et al. Clinical implications of immunoreactivity of thymidylate synthase and dihydropyrimidine dehydrogenase in gastric cancer treated with oral fluoropyrimidine (S-1). Study group of S-1 for gastric cancer. Int J Oncol 2000;17:653-58. 